\title{
Taste Terms in the Patani Malay Ethnic Group
}

\author{
Nuntana Wongthai (นันทนา วงษ์ไทย) \\ Assistant Professor, Center for Graduate Studies (Program of Linguistics), \\ Faculty of Humanities, Srinakharinwirot University, Thailand \\ nuntanaw@g.swu.ac.th
}

\begin{abstract}
This paper reveals the concepts of taste in the Patani Malay ethnic group. Forty-five Patani Malays living in Pattani province, Yala province, and Narathiwat province participated in this study. The analysis uses the framework of componential analysis in ethnosemantics. The results show that there are ten basic taste terms in the Patani Malay dialect: /mase/ 'sour', /masey/ 'salty', /manih/ 'sweet', /pahe?/ 'bitter', /licah/ 'a little bit spicy and causing tongue pain', /lita/ 'unpleasant taste, sticking on the tongue and causing tongue numbness', /k k tawa/ 'bland'. All of them are distinguished by eight dimensions: taste buds, tongue side, tongue tip, acidity, tongue body, pain, tongue numbness, and nuttiness. Besides using each taste term individually to describe tastes of food, Patani Malays also use them repeatedly, combine each taste term together, and combine them with modifiers.

From these ten basic taste terms, there are two taste terms that concern pain in the mouth and on the tongue. These are /licah/ 'a little bit spicy and causing tongue pain' and /pidah/ 'spicy'. This reflects the preference for spicy flavours in the Patani Malay ethnic group. It may be due to the influence of using spices and chili in cooking adopted from foreign countries since ancient times. It may also be due to the geographical characteristics of Pattani, Yala, and Narathiwat provinces, which are located along the coast. People, therefore, prefer eating spicy food to keep their body warm and prevent illness.
\end{abstract}

\section{Keywords}

taste terms - ethnosemantics - Patani Malay 
บทคัดย่อ

คำเรียกรสของกลุ่มชาติพันธุ์มลายูปาตานี

งานวิจัยนี้แสดงให้เห็นมโนทัศน์เกี่ยวกับรสของกลุ่มชาติพันธุ์มลายูปาตานี โดยเก็บข้อมูลจากผู้บอกภาษาที่มีเชื้อสายมลายู ปาตานีที่อาศัยอยู่ในจังหวัดปัตตานี ยะลา และนราธิวาส จำนวน 45 คน กรอบแนวคิดที่ใช้ในการวิเคราะห์ข้อมูลคือการ วิเคราะห์องค์ประกอบทางความหมายในทฤษฎีอรรถศาสตร์ชาติพันธุ์ ผลการศึกษาพบคำเรียกรสพื้นฐานจำนวน 10 คำ ได้แก่ /mase/ 'เปรี้ยว', /masey/ ‘ค็ม', /manih/ 'หวาน', /pahe?/ 'ขม', /licah/'เผ็ดเล็กน้อยและมีความแสบลิ้น', / $\mathrm{lita} /$ 'เผื่อน ติดลิ้น และมีความชาลิ้น', / $\mathrm{k}^{\mathrm{h}}$ ila? / 'ฝาด', /pidah/ ‘ผ็ด', /limo?/ 'มัน' และ/tawa/ 'จืด' คำเรียกรส ดังกล่าวแตกต่างกันด้วย 8 มิติ ได้แก่ มิติปุ่มรับรสที่ลิ้น มิติข้างลิ้น มิติปลายลิ้น มิติความเป็นกรด มิติการรับรสที่ลิ้น มิติความ แสบ มิติความชาลิ้น และมิติความมัน นอกเหนือจากคำเรียกรสพื้นฐานแล้ว ยังพบคำเรียกรสไม่พื้นฐาน ซึ่งเกิดจากกลวิธีการ สร้างคำ 3 กลวิธี ได้แก่ การซ้ำคำเรียกรสพื้นฐาน การรวมกันของคำเรียกรสพื้นฐาน และการรวมกันของคำเรียกรสพื้นฐานกับ คำขยาย

จากคำเรียกรสพื้นฐานทั้งหมดมีคำเรียกรสจำนวน 2 คำที่แสดงความหมายเกี่ยวกับความแสบที่ลิ้นและในช่องปาก ได้แก่ / licah/ 'เผ็ดเล็กน้อยและมีความแสบลิ้น' และ /pidah/ 'เผ็ด' การพบคำเรียกรสที่มีความหมายเกี่ยวข้องกับรสเผ็ดถึง 2 คำ ในกลุ่มชาติพันธุ์มลายูปาตานีแสดงให้เห็นว่าชาติพันธุ์มลายูปาตานีนิยมรับประทานรสเผ็ด ซึ่งอาจเนื่องมาจากการรับอิทธิพล จากต่างประเทศในการนำเครื่องเทศและพริกมาเป็นวัตถุดิบในการปรุงอาหารตั้งแต่อดีต และอาจเนื่องด้วยสภาพทางภูมิศาสตร์ ของ 3 จังหวัดดังกล่าวที่อยู่ติดทะเล จึงนิยมรับประทานอาหารรสเผ็ด เพื่อช่วยทำให้ร่างกายอบอุ่นและป้องกันการเจ็บป่วย

\section{$1 \quad$ Introduction}

Language and culture are interrelated. Different languages reflect different worldviews. Some languages have words for things that others do not. Ethnosemantics is one of the fields exploring how the words people use to describe a particular subject (or semantic domain) reveal the way they perceive the world (Ottenheimer 2013: 18-23). One of the semantic domains which can clearly demonstrate the relation between language and culture, and thus interests ethnosemanticists is the semantic domain of taste terms.

This paper aims to investigate and compare the taste terms used in the $\mathrm{Pa}$ tani Malay dialect, a dialect spoken by Malay-Muslims living in the provinces of Pattani, Yala, and Narathiwat. Although they use the same dialect, there may be some differences across the provinces. Patani Malay is the most popular dialect in the southern part of Thailand (Royal Institute 2010: 5); however, no previous studies have been found on the taste terms in this dialect. This topic is thus worth studying. The results of the study are hoped to offer a way to promote a better and more profound understanding of Patani Malay's food culture and to provide an insight into how Patani Malay people perceive and categorize the world. 
According to the Royal Institute (2010: 5), Patani Malay is a dialect of the Malay language which is spoken in the old Patani State. The old Patani State covered the areas of Pattani province, Yala province, Narathiwat province and Chana, Thepha, Nathawee, and Sabayoy districts in Songkhla province. It is categorized into the Austronesian language family or Malayo-Polynesian. In the southern part of Thailand, there are many Malay dialects such as Satun Malay, Nakhon Si Thammarat Malay, Urak Lawoi. However, the most popular Malay dialect is Patani Malay. Premsrirat et al. (2004: 187) claim that people in $82 \%$ of the areas in the provinces of Pattani, Yala, and Narathiwat use Patani Malay in their daily life.

Patani Malay is not a written language and it has no alphabet. To write this language one can either use a modification of Jawi, an Arabic alphabet, or Rumi, a Roman alphabet. Baru et al. (2008: 99) claim that Patani Malay has the same characteristics as a dialect spoken in Kelantan, Malaysia, due to the contact and migration of Muslims between these two areas.

The name of the Patani Malay dialect is often confused with Pattani Malay, which refers to a dialect of standard Malay spoken only in Pattani province. However, upon interviewing informants about the difference of Patani Malay, Pattani Malay and standard Malay, it was found that Patani Malay and Pattani Malay differ only in some lexemes and accents. However, these two dialects are quite different from standard Malay. For example, the sentence meaning 'I eat rice with deep-fried fish' can be said in these three dialects as follows.

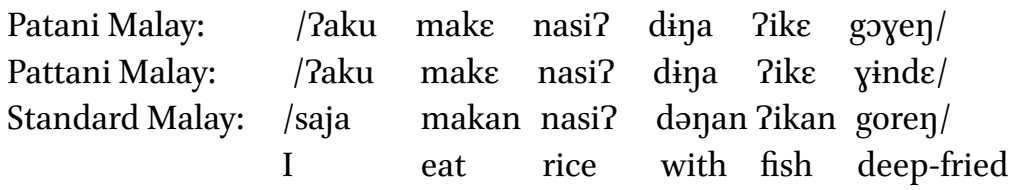

Taste terms are terms used to refer to tastes of food in a particular language. The study of taste terms is one of the most popular topics in ethnosemantics, especially within the componential analysis approach. The results of studies reveal many distinct taste terms used in different languages and dialects (Backhouse 1994, Jirananthanaporn and Singnoi 2010, Mekbantoon 2004, Phasukit 2004). Results from previous studies demonstrate that taste perception 
concerns various dimensions, and not only taste buds in the tongue. Moreover, they reveal the fact that differences in geographical characteristics, which generate differences in food and culture, also affect taste terms.

In the Thai context, Phasukit (2004) analyzed taste terms in fourThai dialects: Bangkok, Chiang Mai, Ubon Ratchathani and Nakhon Si Thammarat. She found that all four dialects have eight common basic taste terms representing eight basic taste categories: / priaw $^{3} /$ (SOUR), / wa: $^{5} /$ (SWEET), $/ \mathrm{k}^{\mathrm{h}} \mathrm{em}^{1} /$ (SALTY), $/ \mathrm{k}^{\mathrm{h}} \mathrm{Om}^{5} /$ (BITTER), $/ \mathrm{p}^{\mathrm{h}} \mathrm{et}^{2} /$ (HOT), $/ \mathrm{cit}^{2} \mathrm{t}^{2}$ (FLAT), /fa: ${ }^{2} /$ (ASTRINGENT) and $/ \mathrm{man}^{1} /$ (CHEWY). However, the dialects in Chiang Mai and Ubon Ratchathani have two more basic taste terms representing the taste categories of $/ \mathrm{fran}^{2} /$ (UNPALATABLE) and $/ \mathrm{k}^{\mathrm{h}} \mathrm{k}^{2} \mathrm{n}^{2} /$ (ALMOST BITTER), while the Ubon Ratchathani dialect has one more basic taste term representing the taste category of $/ \mathrm{hin}^{1} /$ (NASAL). Jirananthanaporn and Singnoi (2010) studied Tai ethnic taste terms in nine provinces in the lower northern part of Thailand covering 19 Tai sub-dialects and six Tai ethnic groups. The study found 41 taste terms that reveal dimensions of taste perception: taste buds, smell, physical contact, texture, attitude and food name. However, these two studies use different criteria to categorize taste terms. While Phasukit (2004) excluded words referring to feelings and attitude towards the tastes (such as delicious), and words referring to the objects containing the same tastes (such as orange), Jirananthanaporn and Singnoi (2010) did not limit the data in this way. They collected the terms referring to taste perceived by the taste buds, tongue, other sensations (smell, touch) as well as the texture of the food, speakers' attitudes, and food name. Therefore, the data includes the terms such as $/ \mathrm{krosp}^{2} /$ 'crispy' to indicate the texture of the food and /plaa ${ }^{1} \mathrm{raa}^{4} /$ 'fermented fish' to indicate the name of food.

In Teochiu dialect spoken in Bangkok, Mekbantoon (2004) found that there are nine common basic taste terms representing eight basic taste categories, which are $/ \sin ^{1} /$ (SOUR), / tĩ $^{1} /$ or $/$ tĩam $^{5} /\left(\right.$ SWEET), $/$ kiam $^{5} /\left(\right.$ SALTY), $/ \mathbf{k}^{\mathrm{h}} \mathrm{Ow}^{4} /$ (BITTER), /hiaml/, (HOT), /tsia: / (FLAT), /siab²/ (ASTRINGENT), and / $\mathrm{kam}^{1 /}$ (MOIST). From these nine common basic taste terms, there are eight taste terms (except $/ \mathrm{kam}^{1} /$ (MOIST)) which have almost similar meanings to those in Thai dialects found in Phasukit (2004). This reflects the similarity of dining culture between Thai and Chinese.

The study of taste terms has also been found under the framework of the cognitive approach. Laophairoj (2012) studied the conceptual metaphors of taste terms in Thai and Vietnamese. She focuses on four taste terms: sour, sweet, salty, bitter. The study found that the metaphorical concept of taste terms in Thai and Vietnamese is HUMAN QUALITIES ARE TASTES. For example, the taste term $/ \mathrm{k}^{\mathrm{h}} \mathrm{em} 1 /$ 'salty' in Thai can be used metaphorically to mean 'stingy' 
and the taste term /cuə/ 'sour' in Vietnamese can be used metaphorically to mean 'outrageous' as in the following sentences.

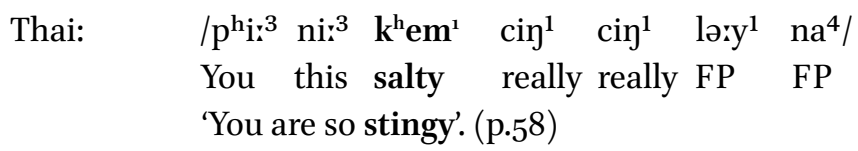

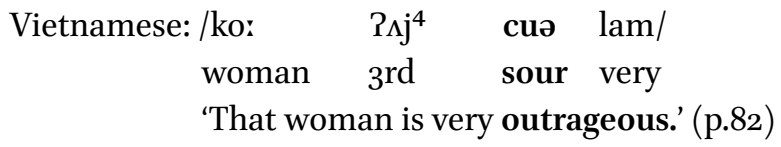

In 2014, Vatanutanon analyzed the extended meanings of nine taste words in Thai, which are / priaw $^{3}$ / 'sour', /wa:n ${ }^{5} /$ 'sweet', $/ \mathrm{k}^{\mathrm{h}} \mathrm{em}^{1} /$ 'salty', $/ \mathrm{k}^{\mathrm{h}} \mathrm{om}^{5} /$ 'bitter', $/ \mathrm{p}^{\mathrm{h}} \mathrm{et}^{2} /$ 'hot', / $\mathrm{cit}^{2}$ / 'flat', /fart ${ }^{2} /$ 'astringent', / $\mathrm{k}^{\mathrm{h}} \mathbf{\mathrm { i }} \mathrm{n}^{2} /$ 'bitterly astringent', and $/ \operatorname{man}^{1} /$ 'chewy'. The results show that those taste words extend their literal meanings to refer to action, appearance, atmosphere, body parts, character, clothing, color, emotion, event, feeling, idea, life, things, as well as other sensations which are smelling, hearing and seeing. The meaning extensions are motivated by metaphorical and metonymic processes. The following example is a meaning extension from taste to action.

$/ \mathrm{kop}^{2} \mathrm{su}^{2} \mathrm{wa}^{4} \mathrm{nan}^{1} \mathrm{yim}^{4}$ wa:n
Name of superstar smile sweet pretty ${ }^{3} \mathrm{rak}^{4} \quad \mathrm{di}^{1} /$
'Kob Suwanan smiles (sweetly) nicely.' (p.39)

\section{$4 \quad$ Data Collection and Analytical Framework}

The methods adopted in the present study involved interviews and text collection. For the interviews, a one-on-one informal interview of 15 informants (five informants for each province) was carried out. The total number of informants for this study was 45 . The informants were native speakers from Pattani province, Yala province and Narathiwat province. They were from the Patani Malay ethnic group, aged 40 years and up, and had never moved away from their hometown. Their occupations were chefs and food retailers, which ensured they were all familiar with tasting food. During the fieldwork, a native speaker of Patani Malay assisted as an interpreter to ask the questions to the informants in the local dialect and to communicate the information back to the researcher in Thai. This method made the informants feel comfortable to think and answer in their own language. During the interviews, the 
conversation between the informants, the interpreter and the researcher were also recorded upon the informants' permission in order to be used later for analysis.

For the text collection, the researcher collected the Patani Malay menus from southern food cookbooks. Five hundred and forty-three menu items both main dish menu items and dessert menu items were found from the cookbooks. Then a list containing all 543 menu items was constructed to check with the informants to be certain that these reflected the local menu of the Patani Malay ethnic group. If even one informant disagreed with any menu item, it was crossed off the list. The informants confirmed 63 main dish menu items and 46 dessert menu items as local to the Patani Malay ethnic group. The informants were also asked about other local menu items besides those found in the list, and they provided 14 more main dish menu items and 17 more dessert menu items. Therefore, the total number of menu items used in this study was 140 .

After gathering the menu items, the researcher constructed a list of all 140 menu items to ask the informants about the ingredients they used to cook each item on the list. The question used to elicit the data was 'What ingredients do you use in cooking ... (menu item) ...?' a total of 193 ingredients was found from the main dish and dessert menu items. Then, the informants were asked about the taste of all the ingredients, as well as a description of each taste. The questions used to ask the informants were 'When you eat ... (name of ingredient) ..., how does it taste?' and 'Could you please describe that taste?' The data from each informant was recorded in the form constructed with columns to write the taste terms of each ingredient and its description.

After finishing the data collection process, all data were analyzed under the framework of ethnosemantics, which is the study of meaning across cultures, whether by looking at differences in what is meant by words with the same apparent referent, by discovering ways of organizing knowledge or theories about the attribution of meaning, and/or by seeking to identify universals in what people signify and the ways they do so (Leavitt 2015: 52). Prasithrathsint et al (2012: 4) claim that the objective of ethnosemantics is to provide access to the cognitive system, which includes a system of knowledge, ideas and concepts for any ethnic group by analyzing the meanings of words in those ethnic groups. By applying the componential analysis approach (Nida 1979), this study sheds light on the organizational dimensions of distinctive features in Patani Malay's system of taste terms.

Prasithrathsint et al. (2012: 14-15) explain that in the componential analysis approach, each word can be deconstructed into many semantic components or semantic features. The analysis begins with the identification of the 
dimensions of contrast that distinguish the words in question from each other. Then, the semantic features under each dimension of contrast are determined. Löbner (2013: 228-229) mentions that the semantic features are binary with the value + or - and the common practice is to write the semantic features in square brackets and with small capital letters, [+FEMALE] for the word 'girl', for example.

Componential analysis has also been used to analyze many semantic domains (such as colors and kinship) to reveal the important semantic features by which speakers of a particular language distinguish different words in those semantic domains (Ottenheimer 2013: 26). The approach seems to suit best the analysis of the taste terms in Patani Malay, as it can reveal dimensions of contrast and important semantic features that underline the denotative meanings of taste terms in this dialect.

After reviewing the previous studies about taste terms (Jirananthanaporn and Singnoi 2010, Mekbantoon 2004, Phasukit 2004), this study applied the criteria used in Phasukit (2004) and Mekbantoon (2004) to categorize the taste terms in Patani Malay into two groups: basic taste terms and non-basic taste terms. The criteria for considering the basic taste terms were as follows: (a) the taste terms must be monolexemic; (b) they must be used to refer to distinct tastes; (c) they must be able to co-occur with the word /yaso/ 'taste'; (d) they must not be words referring to objects containing the same tastes, and (e) they must not be words referring to other sensations, degree, and/or duration. The criteria for the non-basic taste terms were those which did not match the criteria for the basic ones, except for criterion (c). When the data was collected, the criteria for selecting the taste terms for analysis were that the terms must be used and understood by all informants.

It should be noted that the umami taste was not included in this study although it is scientifically proven to be another basic taste besides sour, sweet, salty and bitter. This is because there are no clear and distinct words used to describe this type of taste in Thai. Even in English, there are only synonyms such as savory and meaty to describe the taste of umami.

The results of this study can be divided into three parts: the basic taste terms, the non-basic taste terms, and the comparison of taste terms in three provinces.

\subsection{Basic Taste Terms in Patani Malay}

The study found 10 basic taste terms in Patani Malay, which are as follows: 


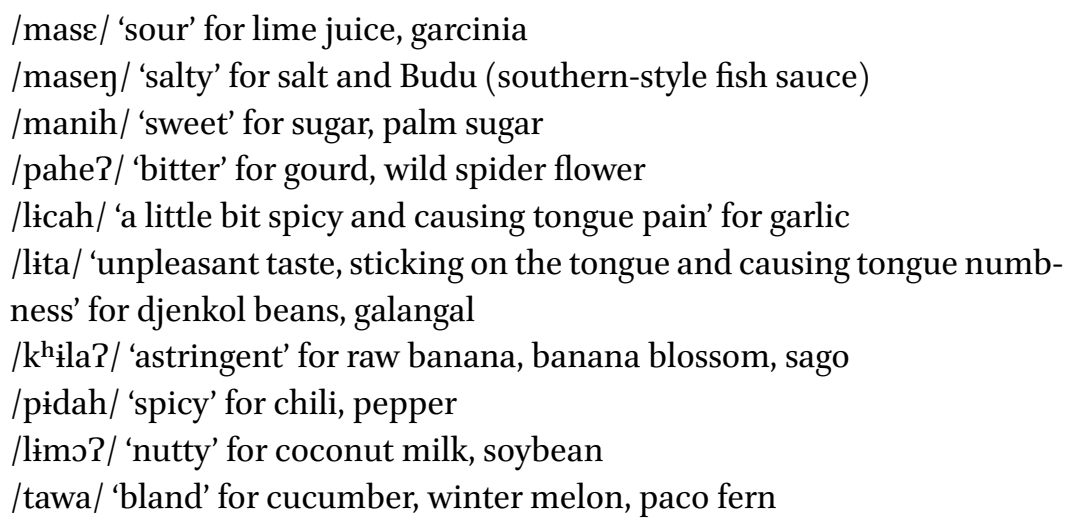

The data gained from the informants about the descriptions of each taste term facilitated the construction of the dimensions of the taste term system. Basic taste terms in Patani Malay are based on eight dimensions, which are TASTE BUDS, TONGUE SIDE, TONGUE TIP, ACIDITY, TONGUE BODY, PAIN, TONGUE NUMBNESS, and NUTTINESS. Following are the details of each dimension and the binary features under each. Note that the binary features are represented by the + and - signs. A feature with $a+$ sign and a feature with a - sign under the same dimension are opposite to each other. For example, [+TASTE BUDS] means that the taste term signifies the taste perceived by taste buds, while [-TASTE BUDS] means the taste perceived by the tongue body and oral cavity, not by the taste buds.

\subsubsection{Taste Buds}

This dimension is about the taste buds in the tongue area. Goldstein (2007:339) explains that the process of tasting begins with the tongue. The surface of the tongue contains papillae, which can be divided into four types: filiform papillae, which are found over the entire surface of the tongue; fungiform papillae, which are found at the tip and sides of the tongue; foliate papillae, which are along the back of the tongue on the sides; and circumvallate papillae, which are found at the back of the tongue.

All papillae except the filiform papillae contain taste buds. The whole tongue contains around 10,000 taste buds (Bartoshuk 1971 cited in Goldstein 2007: 339). The feature [+TASTE BUDS] signifies the taste terms that refer to the tastes perceived by the taste buds. The taste terms which contain this feature are /mase/ 'sour', /masey/ 'salty', /manih/ 'sweet', and /pahe?/ 'bitter'.

The feature [-TASTE BUDS] signifies that the taste terms are perceived by the tongue body and the oral cavity, not by the taste buds. The taste terms which contain this feature are /licah/ 'a little bit spicy and causing tongue pain', 
/lita/ 'unpleasant taste, sticking on the tongue and causing tongue numbness',

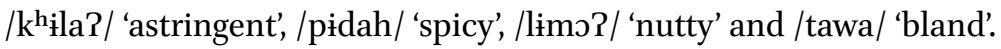

McLaughlin (2007: 230) claims that different parts of the tongue are sensitive to different tastes. The tip of the tongue is preferentially sensitive to sweet, while the sides of the tongue respond better to sour and salty flavors. The back of the tongue is more sensitive to bitter taste. Therefore, the dimensions of tongue side and tongue tip are needed to distinguish the taste terms.

5.1.2 Tongue Side

The dimension [TONGUE SIDE] means that the taste is perceived by using the side of the tongue. The tastes perceived by this part are /mass/ 'sour' and /masey/ 'salty'. Therefore, these terms contain the feature [+TONGUE SIDE]. The taste terms which are not perceived by the taste buds on the side of the tongue but on other areas are /manih/ 'sweet' and /pahe?/ 'bitter'. They, therefore, contain the feature [-TONGUE SIDE].

\subsubsection{Tongue Tip}

The taste terms under the feature [-TONGUE SIDE] can be distinguished from each other by the dimension [TONGUE TIP], which means that the taste is perceived by using the tip of the tongue. The term with the feature [+TONGUE TIP] is /manih/ 'sweet' and the opposite [-TONGUE TIP] is /pahe?/ 'bitter' which is perceived by the back of the tongue.

\subsubsection{Acidity}

The dimension of acidity concerns the chemical substance of sourness. This dimension is used to differentiate sourness and saltiness because these two tastes are perceived by the taste buds on the side of the tongue. The taste term which contains the feature [+ACIDITY] is /mase/ 'sour', while the taste term containing the opposite feature [-ACIDITY] is /masey/ 'salty'.

\subsubsection{Tongue Body}

Due to the fact that some tastes cannot be perceived by the taste buds, tongue side, and tongue tip, but rather are perceived by the tongue body and the oral cavity, the feature [+TONGUE BODY] needs to be used to signify three taste terms: /licah/ 'a little bit spicy and causing tongue pain', /lita/ 'unpleasant taste, sticking on the tongue and causing tongue numbness' and $/ \mathrm{k}^{\mathrm{h}}$ ila? / 'astringent' which are perceived by the tongue body. In contrast, the feature [-TONGUE BODY] is used to signify another three taste terms which are perceived by the oral cavity: /pidah/ 'spicy', /limo?/ 'nutty' and /tawa/ 'bland'. 


\subsubsection{Pain}

The informants also provided information that some kinds of food, like chili and garlic, caused pain in their mouth. The feature [+PAIN] is therefore used with /licah/ 'a little bit spicy and causing tongue pain' under the feature [+TONGUE BODY] and /pidah/ 'spicy' under the feature [-TONGUE BODY]. In contrast, the feature [-PAIN] is used with $/ \mathrm{k}^{\mathrm{h}}$ ila? / 'astringent' under the feature [+TONGUE BODY], /limo?/ 'nutty', $/ \lambda_{1} \tau \alpha /$ 'unpleasant taste, sticking on the tongue and causing tongue numbness' and /tawa/ 'bland' under the feature [-TONGUE BODY] because these tastes cause no pain in the mouth.

\subsubsection{Tongue Numbness}

Some foods such as djenkol beans and galangal make the tongue numb. This dimension is needed to signify the taste term under the feature [-PAIN] which causes tongue numbness. The feature [+TONGUE NUMBNESS] is used with /lita/ 'unpleasant taste, sticking on the tongue and causing tongue numbness', whereas the feature [-TONGUE NUMBNESS] is used with $/ \mathrm{k}^{\mathrm{h}}$ ila?/ 'astringent'.

\subsubsection{Nuttiness}

The informants said that when they chewed some kinds of food (nuts, offals, for example), they could feel the nuttiness in the oral cavity but they could not describe the taste. However, they confirmed that the perception of this taste is different from other tastes. The taste term with the feature [+NUTTINESS] is /limo?/'nutty' and the taste term in the opposite feature [-NUTTINESS] is /tawa/ 'bland'.

The analysis of the dimensions and distinctive features of the basic taste terms in Patani Malay is shown in Table 1.

Table 1 shows that there are more taste terms under the feature [-TASTE BUDS] than under the feature [+TASTE BUDS] (6 terms vs. 4 terms). This reveals that the concept of taste of Patani Malay is not constructed only by the taste buds, but also by other dimensions. It also shows that in Patani Malay there are two taste terms under the feature [+PAIN], which are /licah/ and /lita/. This reveals a preference for spicy taste in this ethnic group.

\subsection{Non-basic Taste Terms in Patani Malay}

The use of taste terms in Patani Malay also includes non-basic taste termsi.e., taste terms which are not monolexemic. These are formed by using three linguistic strategies: the repetition of basic taste terms, the combination of basic taste terms, and the combination of basic taste terms with modifiers. 


\begin{tabular}{|c|c|c|c|c|c|c|c|c|c|c|c|c|}
\hline & & [SSANILLONN-] & & & & & & & & & & - \\
\hline & 点 & [SSANILLONN+] & & & & & & & & & - & \\
\hline & 乐至 & $\begin{array}{c}\text { [SSANGWחN } \\
\text { BดЭNOL-] }\end{array}$ & & & & & & & & & & \\
\hline & 兄 & $\begin{array}{c}\text { [SSANGWON } \\
\text { BดつNOL'] }\end{array}$ & & & & & & & & & & \\
\hline & & {$\left[\mathrm{NIVd}^{-}\right]$} & & & & & & & & & & \\
\hline & $\widehat{\Omega}$ & {$\left[\mathrm{NIVd}^{+}\right]$} & & & & & - & & & -7 & & \\
\hline & 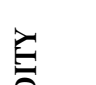 & [XILIGIOV-] & & - & & & & & & & & \\
\hline & Ë & [X.LIGIOV+] & - & & & & & & & & & \\
\hline & 됙 & [хণоя สกЭNOL ${ }^{-}$] & & & & & & & & - & - & - \\
\hline & 它 & 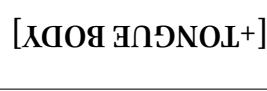 & & & & & - & - & - & & & \\
\hline & $\sum_{0}^{1}$ & [dIL GกDNOL-] & & & & - & & & & & & \\
\hline & $\overbrace{}^{-1}$ & [dIL GกDNOL+] & & & - & & & & & & & \\
\hline & 兆 & [GđIS вกЭNOL-] & & & - & - & & & & & & \\
\hline & o s & [gđIS вกગNOL ${ }^{+}$] & - & - & & & & & & & & \\
\hline$\stackrel{2}{0}$ & $\overbrace{\infty}^{\infty}$ & [SGกg GLSVL-] & & & & & - & - & - & - & - & - \\
\hline$\stackrel{\bar{d}}{g}$ & 占 & [SGกggLSHL+] & - & - & - & - & & & & & & \\
\hline 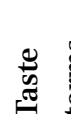 & & & $\begin{array}{l}\bar{w} \\
\tilde{\Xi} \\
\tilde{\Xi} \\
\underline{\Xi}\end{array}$ & $\begin{array}{l}\vec{\Xi} \\
\mathbb{\Xi} \\
\vec{\Xi}\end{array}$ & 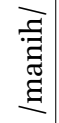 & 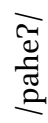 & 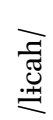 & 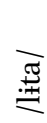 & 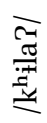 & 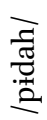 & 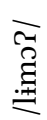 & $\sum^{\pi}$ \\
\hline
\end{tabular}




\subsubsection{The Repetition of Basic Taste Terms}

This strategy describes the intensity of tastes. The data shows that every basic taste term can be used repeatedly. However, the change in meaning depends on the way the speakers pronounce the term. If the speakers put stress on the first part, it means an increased intensity of the taste. For example, /ma'nih manih/ means very sweet. On the contrary, if they place the same amount of stress on both parts, it means a low intensity of the taste. For example, /manih manih/ means a little bit sweet. Other examples are /ma's $\varepsilon$ mase/ 'very sour', / mase mase/ 'a little bit sour'; /pi'dah pidah/ 'very spicy', /pidah pidah/ 'a little bit spicy'.

\subsubsection{The Combination of Basic Taste Terms}

The basic taste terms can be combined to make a non-basic taste term consisting of up to four terms. The combination of two different basic taste terms is found with most frequency, such as /masen limo?/ 'salty and nutty', /pidah manih/ 'spicy and sweet'. Examples of non-basic taste terms with three basic taste terms are /manih masen limo?/ 'sweet, salty and nutty', /masen pahe? manih/ 'salty, bitter and sweet'. The taste term /mase manih masen pidah/ 'sour, sweet, salty and spicy' is an example of non-basic taste terms consisting of four basic taste terms. However, the informants said that the order of the taste terms in the combination can change depending on the perception of the prominent taste. This strategy helps describe the taste of food more clearly because some foods may contain more than one taste.

\subsubsection{The Combination of Basic Taste Terms with Modifiers}

Basic taste terms in Patani Malay also occur with other words which help modify their meanings. These words describe degrees of taste, duration and other sensations.

\subsubsection{The Combination of Basic Taste Terms and Words Describing Degrees of Taste}

The basic taste terms can occur with words expressing more intensity and those expressing less intensity. The words expressing more intensity are / d:o?oh/ 'too', /kuwa?/ 'strong', and /tafe/ 'pointed'. For example, /manih taje/ means strongly sweet. The words expressing less intensity are /haluh/ 'small' /kuyc/ 'not quite' and /siki?/ 'a little'. For example, /pidah haluh/ means a little bit spicy. Note that they always occur after the taste terms. However, these words cannot occur with the taste term /licah/ 'a little bit spicy and causing tongue pain'. 
There are four basic taste terms /manih/ 'sweet', /masey/ 'salty', /mase/ 'sour', /pidah/ 'spicy' that can occur with collocates: /litiy/, /piya?/, /puyi?/ and /biney/ respectively. The informants state that these collocates are never used individually to signify anything. They occur only with those four taste terms to emphasize the highest degree of the taste. The term /manih/ 'sweet' always collocates with /litin/ to mean very sweet; the term /masey/ 'salty' with /piya?/ to mean very salty; the term /mase/ 'sour' with /puyi?/ to mean very sour; the term /pidah/ 'spicy' with /biney/ to mean very spicy.

$5 \cdot 2 \cdot 3 \cdot 2$

The Combination of Basic Taste Terms and the Words / tube?/ 'out', /no?/ 'will', /no? tube? / 'will out', /no? Pado/ 'will have', and /no? yaso/ 'will taste'

The words /tube?/ 'out', /no?/ 'will', /no? tube? / 'will out', /no? Rado/ 'will have', and /no?yass/ 'will taste' can occur with every basic taste term to indicate a small amount of the taste. For example, /tube? manih/ 'out sweet' means a little sweet. These words can also occur between two basic taste terms to signify a small amount of the taste which comes after. For example, /limo? no? ?ado manih/ 'nutty will have sweet' means that the nuttiness is the prominent taste and the food also has a little bit of a sweet taste.

\subsubsection{The Combination of Basic Taste Terms and the Words Describing Duration}

This linguistic strategy explains the duration of taste. Only the term /pidah/ 'spicy' can occur with words describing duration such as /lams/ 'long' and / sibita/ 'short' in the preceding position, for example, /pidah lams/ 'spicy for a long time' and /pidah sibita/ 'spicy for a short time'. The reason why /pidah/ 'spicy' is the only taste term found in this case can be explained from the componential analysis in Table 1 . It contains the features [-TONGUE BODY] and [+PAIN] which mean painful in the oral cavity. The informants described this kind of pain as lasting for some time.

\subsubsection{The Combination of Basic Taste Terms and Words Describing Other Sensations}

Patani Malay taste terms can occur with words representing the olfactory sense and the tactile sense. Ten words representing the olfactory sense which occur with basic taste terms are /bawu/ 'smell', /banin/ 'scented', /busũ?/ 'stinky', / cinih/ 'pungent smell used for good smell', /haye/ 'fishy smell used for seafood', /hayin/ 'pungent smell used for bad smell', /hamih/ 'fishy smell used for meat', /maw ${ }^{\text {w }}$ / 'rank', /tini?/ 'musty smell', and /wonin/ 'fragrant'. The term /lita/ 'unpleasant taste, sticking on the tongue and causing tongue numbness' does not 
co-occur with these words. Five words in the tactile sense that occur with basic taste terms are /biyaniy/ 'breezing', /panah/ 'hot', /pideh/ 'painful', / yapoh/ 'crispy', and / jite?/ 'painful on skin'. The taste terms /licah/ 'a little bit spicy and causing tongue pain', /lita/ 'unpleasant taste, sticking on the tongue and causing tongue numbness', and $/ \mathrm{k}^{\mathrm{h}}$ ila? / 'astringent' do not co-occur with these words.

\subsection{The Comparison of Taste Terms in Three Provinces}

As mentioned above, Patani Malay is the dialect spoken in Pattani province, Yala province, and Narathiwat province. Even though people in these three provinces use the same dialect, there may be some differences across the provinces. It is, therefore, interesting to investigate the number of basic taste terms people in these provinces use, the types of linguistic strategies they use to form non-basic taste terms, and the prominent taste of these three provinces.

The findings show that people in these three provinces use the same number of basic taste terms and use the same linguistic strategies in forming nonbasic taste terms. However, for the prominent taste, it is surprisingly found that /tawa/ 'bland' is used in the highest frequency to indicate the taste of the ingredients used in cooking the local menus of the Patani Malay ethnic group. The overall frequency of each taste term in Patani Malay is shown in Table 2. The basis of the calculation is the percentage of the total number of ingredients (193) found in the data collection and the number of taste terms the informants refer to for each ingredient.

The overall frequency in Table 2 shows that /tawa/ 'bland' occurs with the highest frequency $(24.70 \%)$. The second most frequent term is /manih/ 'sweet' $(21.42 \%)$, followed by /pidah/ 'spicy' (18.48\%). The taste terms found in the least frequency are /limo?/ 'nutty', /masey/ 'salty', /mase/ 'sour', /pahe?/ 'bitter', $/ \mathrm{k}^{\mathrm{h}}$ ila? / 'astringent', /licah/'a little bit spicy and causing tongue pain', and /lita/ 'unpleasant taste, sticking on the tongue and causing tongue numbness'.

The frequency of each basic taste term used by the informants from each province is shown in Table 3 .

Table 3 shows that the three taste terms found with most frequency in Pattani province and Yala province are /tawa/ 'bland', /manih/ 'sweet' and /pidah/ 'spicy' respectively. However, in Narathiwat Province /manih/ 'sweet' is the most frequent term $(24.35 \%)$ and /tawa/ 'bland' the second most $(23.32 \%)$, although these percentages are not very different. The taste terms found with the least frequency in the three provinces are the same: /limo?/ 'nutty', /masey/ 'salty', /mase/ 'sour', / pahe?/ 'bitter', /knitla?/ 'astringent', /licah/ 'a little bit spicy and causing tongue pain', and /lita/ 'unpleasant taste, sticking on the tongue and causing tongue numbness' as the data in Table 2 shows. 
TABLE 2 The overall frequency of each taste term in Patani Malay

\begin{tabular}{lc}
\hline Taste terms & $\%$ \\
\hline /tawa/ 'bland' & 24.70 \\
/manih/ 'sweet' & 21.42 \\
/pidah/ 'spicy' & 18.48 \\
/limə?/ 'nutty' & 12.61 \\
/masey/ 'salty' & 8.46 \\
/mase/ 'sour' & 7.43 \\
/pahe?/ 'bitter' & 5.18 \\
/khila?/ 'astringent' & 0.68 \\
/licah/ 'a little bit spicy and & 0.52 \\
causing tongue pain' & \\
/lita/ 'unpleasant taste, sticking & 0.52 \\
on the tongue and causing tongue & \\
numbness' & \\
Total & 100 \\
\hline
\end{tabular}

TABLE 3 The frequency of each taste term from each province

\begin{tabular}{|c|c|c|c|}
\hline \multirow[t]{2}{*}{ Taste terms } & $\begin{array}{l}\text { Pattani } \\
\text { province }\end{array}$ & $\begin{array}{l}\text { Yala } \\
\text { province }\end{array}$ & $\begin{array}{l}\text { Narathiwat } \\
\text { province }\end{array}$ \\
\hline & $\%$ & $\%$ & $\%$ \\
\hline /manih/'sweet' & 19.69 & 20.21 & $24 \cdot 35$ \\
\hline /masey/'salty' & 8.29 & 8.29 & 8.81 \\
\hline /mase/ 'sour' & $7 \cdot 77$ & $7 \cdot 77$ & 6.73 \\
\hline /pahe?/ 'bitter' & $5 \cdot 70$ & 6.22 & 3.63 \\
\hline /licah/ 'a little bit spicy and causing tongue pain' & $0.5^{2}$ & $0.5^{2}$ & $0.5^{2}$ \\
\hline $\begin{array}{l}\text { /lita/ 'unpleasant taste, sticking on the tongue } \\
\text { and causing tongue numbness' }\end{array}$ & $0.5^{2}$ & $0.5^{2}$ & $0.5^{2}$ \\
\hline /k $\mathrm{k}^{\mathrm{h}}$ ila? / 'astringent' & 1.04 & $0.5^{2}$ & $0.5^{2}$ \\
\hline /pidah/ 'spicy' & 18.13 & 18.65 & 18.65 \\
\hline /limo?/'nutty' & 11.92 & 12.95 & 12.95 \\
\hline /tawa/ 'bland' & 26.42 & $24 \cdot 35$ & $23 \cdot 3^{2}$ \\
\hline Total & 100 & 100 & 100 \\
\hline
\end{tabular}


The results of this study illuminate the folk concept of taste in the Patani Malay ethnic group, which is constructed not only from taste bud parameters, but also from the connection with the tongue body, various parts of the tongue, the oral cavity and other sensations. This is revealed from the dimensions found in the semantic analysis of the taste terms. Moreover, in Patani Malay, there are not only basic taste terms which are monolexemic, but also non-basic taste terms which are formed by various linguistic strategies.

The findings in Table 2 and Table 3 reveal a very interesting fact which contrasts with what Thai people know about the food in the southern part of Thailand-i.e., that it is known for being very spicy. Therefore, the spicy taste should come in the first order, as in the previous study of Phasukit (2004), where the spicy or hot taste is found to be the prominent taste in the Nakhon Si Thammarat dialect.

As the taste term /tawa/ 'bland' appears in the highest frequency (in Table 2 and Table 3), it must be considered as the prominent taste in the Patani Malay ethnic group. When the informants were asked to provide three kinds of food having this taste, they mentioned only the names of vegetables such as / timun

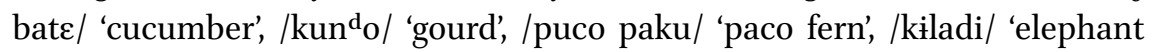
ear', and /mame/ 'wild spider flower'. This reflects that vegetables are an important food for this ethnic group. Sama-ae (2016) found that vegetables are one of the main ingredients found in the semantic features of cooking terms for main dishes, besides rice, meat, chili paste and spices. The preference for eating vegetables may come from the Chinese who came to Thailand in ancient times. They planted many kinds of Chinese vegetables such as Chinese kale, and Chinese morning glory in order to make a living and that broadened the vegetable-eating culture in the southern part of Thailand (Institute of Southern Thai Studies 1986a: 830-831).

However, it is very interesting to discover that from 10 basic taste terms, there are two taste terms, /licah/ 'a little bit spicy and causing tongue pain' and /pidah/ 'spicy', which are categorized under the spicy taste. These findings may reflect the preference for the spicy taste in the Patani Malay ethnic group, even though the term /pidah/ 'spicy' was not found in the first order in the list. The preference for the spicy taste may be influenced by the practice of using spices and chili in cooking, due to contact with Indian and Arab merchants (Narathiwat Provincial Cultural Office 2013: 5). It is possible that because they prefer eating spicy foods, they need to eat vegetables as a side dish. The Institute of Southern Thai Studies (1986b: 2134) mentions that people in the southern part always eat ผักเหนาะ/ $/ \mathrm{p}^{\mathrm{h}} \mathrm{ak}^{2}$ nว ${ }^{2} /$ 'fresh vegetables, coconut milk-boiled 
vegetables, and pickled vegetables' with spicy food such as chili paste, which is called น้ำชุบ/na:m ${ }^{4} \mathrm{t}^{\mathrm{h}}{ }^{\mathrm{u}} \mathrm{up}^{4} /$. This may account for the findings where /tawa/ 'bland' and /pidah/ 'spicy' appear with the most frequency.

Comparing the results with the previous study of Phasukit (2004), all the taste terms found in the Nakhon Si Thammarat dialect were also found in Patani Malay. However, the taste terms /licah/ 'a little bit spicy and causing tongue pain' and /lita/ 'unpleasant taste, sticking on the tongue and causing tongue numbness' were not found in the Nakhon Si Thammarat dialect. It can be said that these two taste terms are unique to the Patani Malay ethnic group. The Patani Malay informants in this study use the term /licah/ 'a little bit spicy and causing tongue pain' to refer only to the taste of garlic and use the term / lita/ 'unpleasant taste, sticking on the tongue and causing tongue numbness' to refer to the taste of djenkol beans and galangal. ${ }^{1}$

The taste term used to refer to garlic in the Nakhon Si Thammarat dialect is $/ \mathrm{p}^{\mathrm{h}} \mathrm{et}^{2} /$ 'spicy' which is also used to refer to the taste of chili and pepper. However, Patani Malay people refer to the taste of these foods as /pidah/. For djenkol beans, the informants in the previous study use the term $/ \mathrm{man}^{1} /$ 'nutty' and they also use this term to refer to the taste of other kinds of food such as peanuts and cashew nuts. This contrasts with the Patani Malay people who refer to the taste of nuts as /limo?/.

The way that Patani Malay people use the term /licah/ 'a little bit spicy and causing tongue pain' to refer only to the taste of garlic and the term /lita/ 'unpleasant taste, sticking on the tongue and causing tongue numbness' to refer to the taste of djenkol beans may reflect an importance given to these kinds of food. By interviewing the informants about the ingredients they use for cooking local menus in the data collection, garlic is found to be an important ingredient in cooking main dishes. The importance of garlic may come from the fact that Pattani, Yala and Narathiwat provinces are located along the East coast of Southern Thailand. This area is affected by the northeast monsoon and the southwest monsoon all year long, which bring a humid climate and rainfall to the area (Thepsongkroh 1998: 150). Humidity and rainfall strongly affect people's health and cause diseases, especially in the respiratory system (Institute of Southern Thai Studies 1986c: 2700). Eating garlic can keep the body warm because garlic has properties that boost the immune system and prevent colds. A possible reason to support the importance of djenkol beans to the Patani

1 They use the term /lita/ 'unpleasant taste, sticking on the tongue and causing tongue numbness' with djenkol beans most. For galangal, most of the informants refer to its taste as /pidah/ 'spicy'. 
Malay ethnic group is the fact that it is a local vegetable in the southern part of Thailand. People in the South regularly eat djenkol beans as a side dish with chili paste and other spicy dishes. They can also be eaten both unripe and pickled (Chonchuapsong 1994: 59).

Another interesting discovery is the high frequency of the sweet taste. This can be explained by referring to the data gained from interviewing the informants about the taste of the ingredients they use to cook the local menu items. The sweet taste comes from the ingredients they use for seasoning and making food such as sugar, palm sugar, seasoning sauce, soya sauce, and meat such as fish, shrimp, and chicken, as well as vegetables such as cabbage and carrots. It is possible that because most ingredients contain a sweet taste, this taste appears in the second highest frequency after the bland taste.

\section{$7 \quad$ Conclusion}

The study of taste terms in Patani Malay reveals the taste terms used in the Patani Malay ethnic group (both basic terms and non-basic terms), the dimensions of contrast that make each term different from each other, and the linguistic strategies Patani Malay people use to construct non-basic taste terms. It also helps promote a better and more profound understanding of the dining culture in the Patani Malay ethnic group. As reflected by the ethnosemantics approach, the study emphasizes the interrelationship between language and culture. The findings that there are two taste terms Patani Malay people use to refer to the spicy taste: /licah/ 'a little bit spicy and causing tongue pain' and / pidah/ 'spicy' may reflect the preference for the spicy taste among the Patani Malay ethnic group. The discovery of two taste terms: /licah/ 'a little bit spicy and causing tongue pain' and /lita/ 'unpleasant taste, sticking on the tongue and causing tongue numbness', which are unique to the Patani Malay ethnic group, may reveal the importance of garlic and djenkol beans among them, resulting from the geographical characteristics and the weather conditions in this area.

\section{Acknowledgements}

This research is funded by the Faculty of Humanities, Srinakharinwirot University. The author would like to thank Dr. Meagan Louie and Mrs. Nicole Lasas for comments and proof-reading. 


\section{References}

Backhouse, Anthony Edgar. 1994. The Lexical Field of Taste: A Semantic Study of Japanese Taste Terms. London: Cambridge University Press.

Baru, Worawit, Nik Abdul Rakib Bin Nik Hassan, Waemajid Paramal, Zawawi Padaamin, Dusdao Lertphiphat, Oracha Rakdi and Suraini Sainui. 2008. Melayu Patani: Ethnicity, Identity and Changing. Faculty of Humanities and Social Science, Institute of Southeast Asian Maritime State Studies, Prince of Songkhla University, Pattani Campus. (In Thai).

Chonchuapsong, Lanthom. 1994. Local Vegetables (South): Choice for Production and Consumption. Bangkok: The WVO Office of Printing Mill. (In Thai).

Goldstein, E. Bruce. 2007. Sensation and Perception. 7th edition. CA: Thomson Wadsworth.

Institute of Southern Thai Studies. 1986a. Encyclopedia of Southern Culture 2. Bangkok: Amarin Printing. (In Thai).

Institute of Southern Thai Studies. 1986b. Encyclopedia of Southern Culture 5. Bangkok: Amarin Printing. (In Thai).

Institute of Southern Thai Studies. 1986c. Encyclopedia of Southern Culture 7. Bangkok: Amarin Printing. (In Thai).

Jirananthanaporn, Supattra and Unchalee Singnoi. 2010. Tai Ethnic Taste Terms in the Lower Northern Part of Thailand: A Case Study in Ethnosemantics. Journal of $\mathrm{Hu}$ manities Naresuan University 7.3:1-30. (In Thai).

Laophairoj, Rujiwan. 2012. A Comparative Study on Conceptual Metaphors of Taste Terms in Thai and Vietnamese. Ph.D. Dissertation. Mahidol University.

Leavitt, John. 2015. Ethnosemantics. In the Routledge of Language and Culture, edited by Farzad Sharifian, pp. 51-65. New York: Routledge.

Löbner, Sebastian. 2013. Understanding Semantics. 2nd edition. New York: Routledge.

McLaughlin, Daniel P., Stamford, Jonathan A. and White, David A. 2007. Instant Notes in Human Physiology. Cornwall: Taylor \& Francis Group.

Mekbantoon, Pornladda. 2004. An Ethnosemantic Study of Taste Terms and Taste Attitudes in Teochiu. M.A. Thesis. Chulalongkorn University. (In Thai)

Narathiwat Provincial Cultural Office. 2013. Thai Food Culture: South. Bangkok: The WVO Office of Printing Mill. (In Thai)

Nida, Eugene. 1979. Componential Analysis of Meaning: An Introduction to Semantic Structures. The Hague: Mouton.

Ottenheimer, Harriet Joseph. 2013. The Anthropology of Language: An Introduction to Linguistic Anthropology. New York: Wadsworth.

Phasukit, Anchalika. 2004. An Ethnosemantic Study of Taste Terms in Thai Dialects. M.A. Thesis. Chulalongkorn University. (In Thai). 
Prasithrathsint, Amara, Kantima Rakwongwan, Manasikarn Hengsuwan, and Sirivimol Sukrasorn. 2012. Important People and Main Ideas in Ethnosemantics: Understanding Culture through Language. Bangkok: A.S.P. Publishers. (In Thai)

Premsrirat, Suwilai, Sutcharitlak Diphadung, Eakaphong Suwanket, Aphinya Buasuang, Isara Choosri and Sophana Srichampa. 2004. Ethnolinguistic Maps of Thailand. Bangkok: Office of the National Culture Commission. (In Thai)

Royal Institute of Thailand. 2010. Manual for Thai-Based Patani Malay Writing System. Bangkok: Sahamitr Printing and Publishing Co., Ltd. (In Thai)

Sama-ae, Nura-aa. 2016. Cooking terms in Patani Malay: An Ethnosemantic Study. M.A. Thesis. Srinakharinwirot University. (In Thai)

Thepsongkroh, Praman. 1998. Geography of Southern Thailand: Geopolitics and Field Trip Local Geography. 2nd edition. Songkhla: Department of Geography Thaksin University. (In Thai)

Vatanutanon, Thitikamol. 2014. The Study of Semantic Extension of Taste Words in Thai. M.A. Thesis. Srinakharinwirot University. (In Thai) 